\title{
Pattern formation in a mean field model of electrocortical activity
}

\author{
Lennaert van Veen", Kevin Green \\ From Twenty Second Annual Computational Neuroscience Meeting: CNS*2013 \\ Paris, France. 13-18 July 2013
}

Mean field models of cortical activity describe the electrical potentials and interactions of cortical neuron populations, coarse-grained over the scale of a few macro columns. Such models can be analysed as dynamical systems, in particular as time-dependent partial differential or integrodifferential equations, which may have complicating aspects such as explicit time delays and stochastic terms. We analyse a model of intermediate complexity, formulated by Liley et al. [1]. This model describes an excitatory and an inhibitory population in a simple geometry, on which the effect of long-range connections is represented by a damped wave equations.
Although somewhat rudimentary from a physiological point of view, this model has been shown to predict several features of electrocortical dynamics rather well (see, e.g., $[2,3]$ and refs therein) and is challenging to analyse mathematically. It consists of fourteen coupled partial differential equations with strong nonlinearities.

Where previous analysis on this model, and similar mean-field models, has used drastic simplifications, such as reduction to zero or one spatial dimensions or a single population, we developed tools for parsing the dynamics of the full-fledged equations [4]. Using the open-source library PETSc [5], we have implemented fully implicit

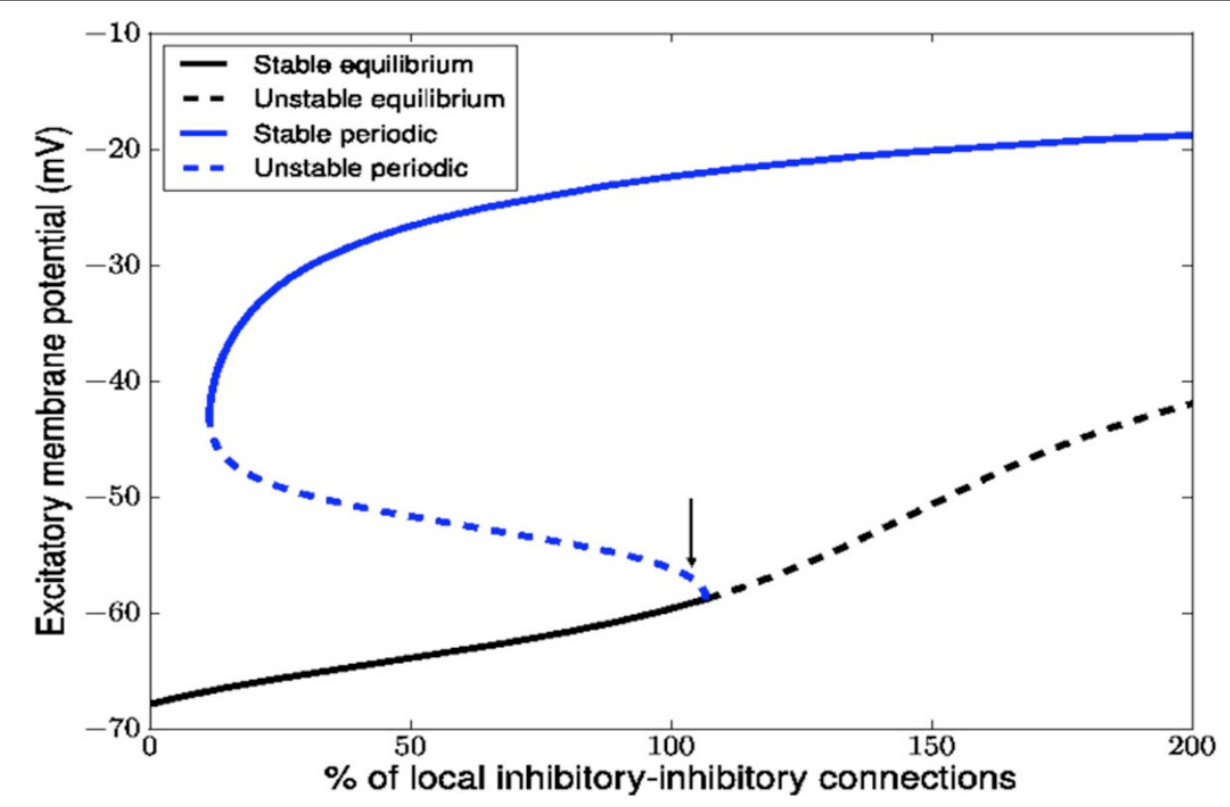

Figure 1 Partial bifurcation diagram near the primary instability, which is a subcritical Hopf bifurcation.

* Correspondence: lennaert.vanveen@uoit.ca

Faculty of Science, University of Ontario Institute of Technology, Oshawa,

Ontario L1H 7K4, Canada 

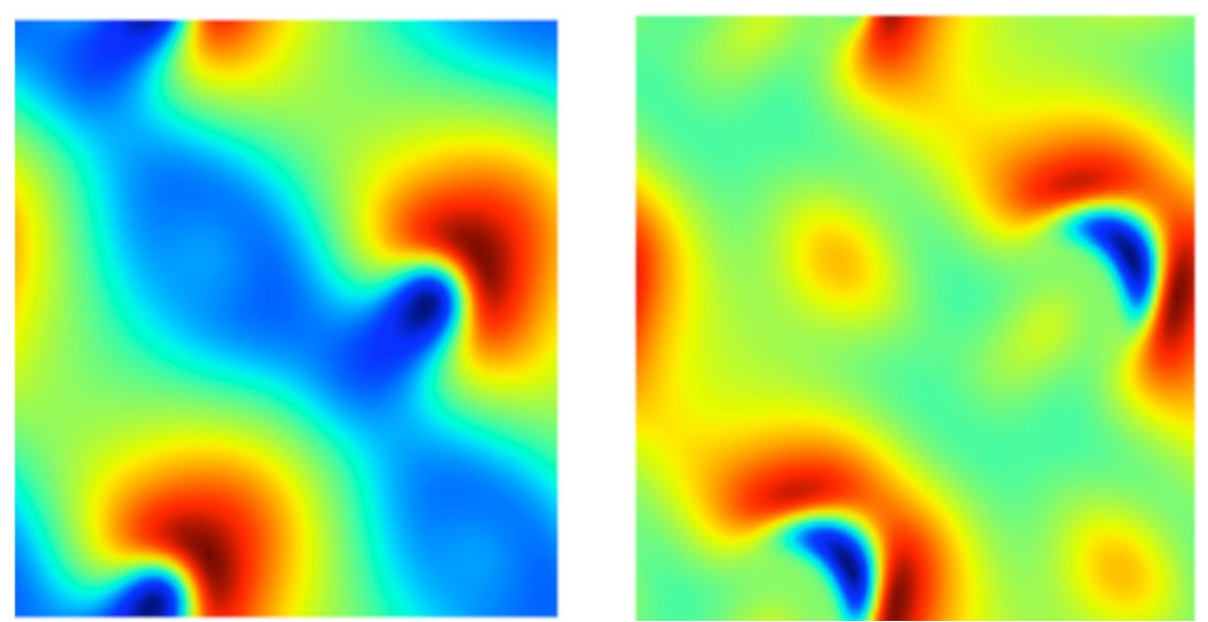

Figure 2 Two snap shots of the excitatory membrane potential along the saddle periodic orbit. The potential ranges from $-67 \mathrm{mV}$ (dark red) to $-52 \mathrm{mV}$ (dark blue).

time-stepping for the field equations and the tangent linear model, as well as arclength continuation for equilibrium and time-periodic solutions. All computations are performed in parallel using domain decomposition.

In the current application of these tools, we focus on physiologically interesting $\gamma$-range activity [3]. This activity is triggered by a Hopf bifurcation under small variations of the local inhibitory to inhibitory connection density. We computed the saddle-type periodic orbit that regulates the transient dynamics of perturbations to the base equilibrium state. Two snap shots of this orbit, computed on a 12.8 by $12.8 \mathrm{~cm}$ domain, with $0.5 \mathrm{~mm}$ resolution, are shown in Figure 1. The period of this orbit corresponds to a $12 \mathrm{~Hz}$ oscillation, whereas the final, attracting, state has a strong $40 \mathrm{~Hz}$ peak in the power spectrum [3].

In ongoing work we are investigating bifurcations of this periodic orbit, which can turn completely stable or give rise to more complicated solutions, such as quasi-periodic or chaotic. This dynamical systems approach to the analysis of mean-field models should give us more insight in the complex model behaviour.

Published: 8 July 2013

\section{References}

1. Liley DTJ, Cadusch PJ, Dafilis MP: A spatially continuous mean field theory of electrocortical activity. Network: comput Neural syst 2002, 13:67-113.

2. Coombes S: Large-scale neural dynamics: Simple and complex. Neurolmage 2010, 52:731-739.

3. Bojak I, Liley DTJ: Self-organized $40 \mathrm{~Hz}$ synchronization in a physiological theory of EEG. Neurocomput 2007, 70:2085-2090.

4. Green KR, van Veen L: Open-source tools for dynamical analysis of Liley's mean-field cortex model, arXiv:1210.4784.

5. Balay S, et al: PETSC users manual. Argonne National Laboratory [http:// www.mcs.anl.gov/petsc], ANL-25/11R3.2.
doi:10.1186/1471-2202-14-S1-P149

Cite this article as: Veen and Green: Pattern formation in a mean field model of electrocortical activity. BMC Neuroscience 2013 14(Suppl 1):P149.

\section{Submit your next manuscript to BioMed Central} and take full advantage of:

- Convenient online submission

- Thorough peer review

- No space constraints or color figure charges

- Immediate publication on acceptance

- Inclusion in PubMed, CAS, Scopus and Google Scholar

- Research which is freely available for redistribution
C Biomed Central 